\title{
CISTO EPIDERMÓIDE DE BAÇO EM CRIANÇA. Relato de caso
}

\author{
Glauco da Costa ALVAREZ*, Marner Lopes da SILVEIRA**, Eduardo Militz da COSTA***, \\ Frederico Valente PAGLIARIN*** e Imaruí COSTA***
}

\begin{abstract}
RESUMO - Apresentação de um caso de cisto esplênico epidermóide em paciente masculino de 13 anos, que apresentou diminuição do apetite, febre e vômitos pós-alimentares e massa abdominal palpável ao exame físico. A ultra-sonografia abdominal demonstrou lesão expansiva na topografia do baço e a tomografia computadorizada revelou lesão homogênea intrínseca do órgão, sem comunicação com pâncreas. À laparotomia observou-se massa cística de grande extensão, realizando-se esplenectomia total, sendo diagnosticado no exame anatomopatológico cisto epidermóide de baço. O paciente evoluiu com desaparecimento dos sintomas. Os cistos esplênicos epidermóides são raros, podendo ser vistos principalmente em crianças e adultos jovens, o que propõe uma origem congênita para esta doença.
\end{abstract}

DESCRITORES - Cisto epidérmico. Baço. Criança.

\section{INTRODUÇÃO}

Cistos esplênicos não-parasitários possuem ocorrência pouco freqüente e podem ser classificados em cistos verdadeiros e falsos. São mais freqüentes na segunda e terceira décadas de vida, mas podem aparecer na infância ${ }^{(5,6)}$.

Cistos verdadeiros (epidermóides ou epiteliais) possuem camada de revestimento epitelial e são de origem provavelmente congênita ou neoplásica. Cistos falsos (pseudocistos) são formados por uma parede de tecido fibroso muitas vezes calcificada, sem camada de revestimento epitelial, tendo origem principalmente traumática $^{(1,3,5)}$. Na maioria dos casos, não apresentam manifestações clínicas e seu diagnóstico está relacionado a exame físico e radiológico de rotina e a achados ocasionais durante laparotomias exploradoras ou operações abdominais devido a outras afecções ${ }^{(7)}$. Nos casos sintomáticos, as manifestações clínicas se devem a sintomas de compressão de vísceras adjacentes, causando dor geralmente localizada em hipocôndrio esquerdo, hemitórax esquerdo, epigástrio, região periumbilical. Sintomas gastrointestinais como vômitos, náuseas, saciedade precoce e plenitude pós-prandial podem também ocorrer ${ }^{(6)}$. Havendo ruptura do cisto esplênico, manifesta-se um quadro de abdome agudo ${ }^{(4)}$.

O diagnóstico é firmado pelo exame histopatológico, sendo os principais métodos de diagnóstico diferencial utilizados a ultra-sonografia abdominal e a tomografia computadorizada de abdome, este mais sensível que o primeiro na identificação de septos (mais comuns em cistos verdadeiros) ou calcificações (mais comuns em cistos falsos) $^{(5)}$.

Trabalho realizado no Departamento de Cirurgia da Universidade Federal de Santa Maria - UFSM, Santa Maria, RS.

* $\quad$ Professor Auxiliar do Departamento de Cirurgia do Curso de Medicina da UFSM.

** Residente de Cirurgia do Hospital Universitário de Santa Maria - HUSM - UFSM.

*** Acadêmicos do Curso de Medicina da UFSM.

Endereço para correspondência: Ac. Eduardo Militz da Costa - Avenida Medianeira, 1286/101 - 97060-002 - Santa Maria, RS. 
Este relato apresenta esta afecção incomum, os métodos diagnósticos disponíveis e seu tratamento.

\section{RELATO DO CASO}

Paciente de 13 anos, masculino, branco, previamente hígido, apresentou quadro evolutivo de diminuição de apetite, saciedade precoce, febre e vômitos pós-alimentares, de início em torno de três meses. Concomitantemente, observou-se aparecimento de abaulamento em hipocôndrio esquerdo e epigástrio. Ao exame físico apresentava abdome assimétrico, com abaulamento em hipocôndrio e flanco esquerdos. A palpação evidenciou massa de consistência elástica, móvel, com limites imprecisos e dolorosa à palpação, abrangendo desde o flanco esquerdo, hipocôndrio esquerdo até epigástrio. Quanto à avaliação laboratorial, foram realizados VHS, hemograma, provas de função renal e hepática, todos dentro da normalidade. A ultra-sonografia abdominal demonstrou lesão expansiva, predominantemente anecóica com ecos em suspensão na topografia do baço, medindo $17 \times 15 \times 13 \mathrm{~cm}$. A tomografia computadorizada revelou lesão homogênea, hipodensa, com leves irregularidades e septações periféricas, provavelmente intrínseca do baço, sem comunicações com corpo e cauda do pâncreas (Fig. 1).

À laparotomia observou-se uma massa cística de paredes finas, abrangendo grande extensão do baço, sem envolvimento de outros órgãos abdominais, sendo, então, realizada esplenectomia total. O exame anatomopatológico da peça cirúrgica mostrou baço pesando $930 \mathrm{~g}$, medindo $21 \times 16 \times 16 \mathrm{~cm}$, com cisto unilocular medindo $16 \times 15 \mathrm{~cm}$ (Fig. 2), com parede interna trabeculada e conteúdo esverdeado e espesso. Microscopicamente a parede era revestida por epitélio escamoso, compatível com o diagnóstico histopatológico de cisto esplênico epidermóide.
O paciente evoluiu com desaparecimento da sintomatologia e sem intercorrências no acompanhamento pós-operatório imediato e tardio.

\section{DISCUSSÃO}

Os cistos esplênicos geralmente são assintomáticos, podendo ser encontrados de forma acidental durante a rotina do exame físico ou em cirurgias abdominais ${ }^{(3,4,6)}$.
Somente apresentam sintomas de compressão quando maiores que $8 \mathrm{~cm}^{(5)}$ como relatado em estudo de 19 crianças com cistos esplênicos congênitos, onde $64 \%$ apresentavam massa abdominal e $78 \%$ dor abdominal $^{(6)}$. Podem também apresentar dor no tórax, ombro esquerdo, hipocôndrio esquerdo, ângulo costovertebral esquerdo e região periumbilical, além de sintomas gastrointestinais como náuseas, vômitos, plenitude, constipação, flatulência e diarréia $^{(3)}$.

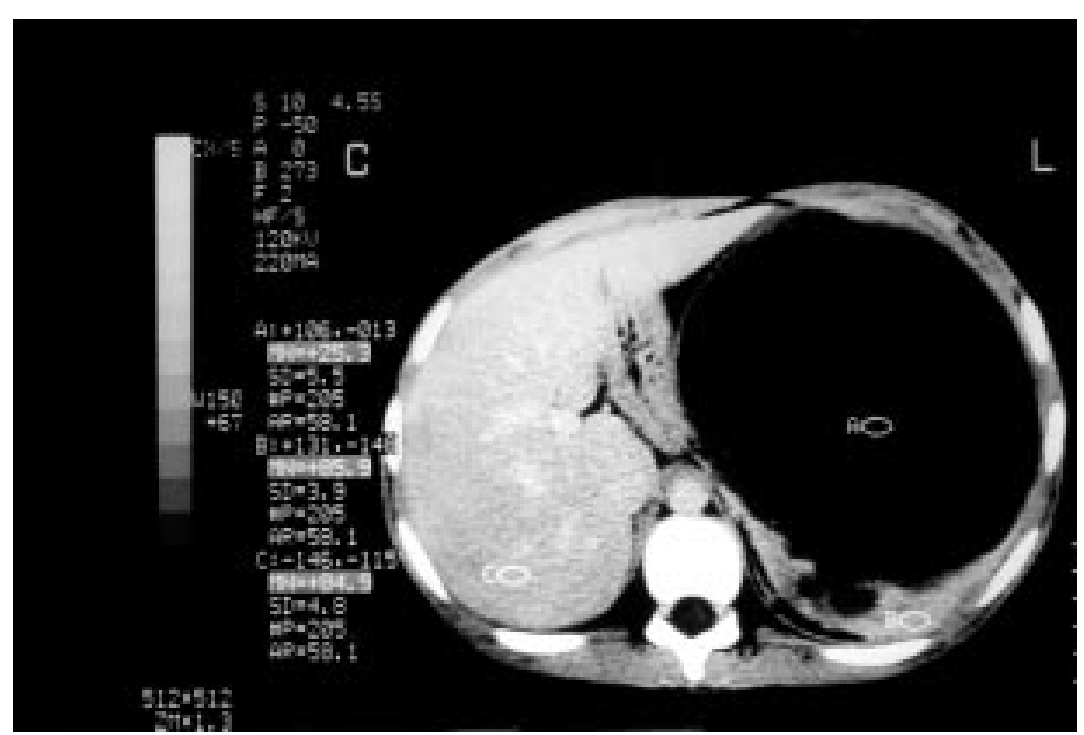

Figura 1 - Tomografia computadorizada. Observa-se grande lesão cística na topografia do baço

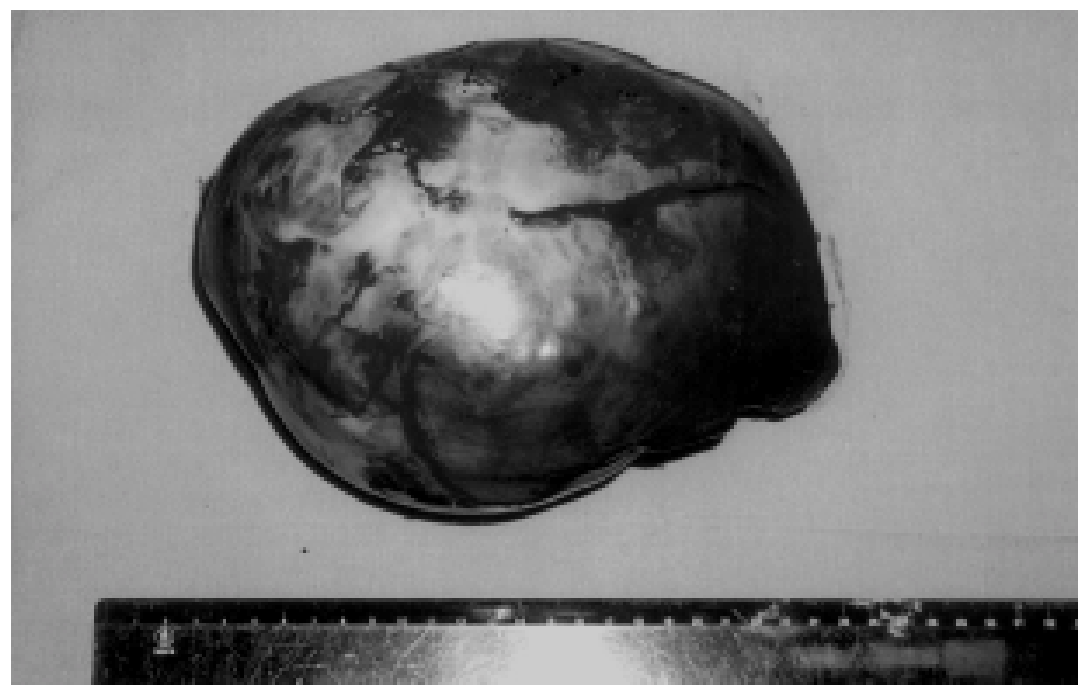

Figura 2 - Baço, produto de esplenectomia, apresentando grande lesão cística 
As técnicas radiológicas modernas têm grande importância no diagnóstico do cisto esplênico, sendo o ultra-som abdominal método eficiente e não-agressivo ${ }^{(1)}$, que mostra a presença do cisto e sua relação com o parênquima esplênico e ou órgãos adjacentes $^{(5,6)}$. A tomografia computadorizada auxilia na diferenciação entre cistos falsos e verdadeiros, já que pode demonstrar a presença de septos, comuns em cistos verdadeiros, ou calcificações das paredes, comuns em cistos falsos ${ }^{(5)}$. A tomografia também contribui para o diagnóstico diferencial com outras patologias, como tumores de órgãos adjacentes ${ }^{(1)}$. Mesmo com o auxílio das técnicas radiológicas, o diagnóstico final é histopatológico.

O tratamento tradicional para o cisto epidermóide de baço é a esplenectomia, utilizada como forma preventiva de infecções, hemorragias ou ruptura do cisto ${ }^{(6)}$, sendo esta realizada no caso em referência. A esplenectomia tem sido bastante utilizada, como mostra um estudo em que sete crianças a ela submetidas, apresentaram remissão dos sintomas e evoluíram sem complicações ${ }^{(3)}$.

Atualmente tem sido realizada hemiesplenectomia ou cistectomia com preservação do tecido esplênico normal, sendo este um método mais seguro, principalmente para crianças e adultos jovens $^{(1,4,6)}$ no sentido de prevenir infecções posteriores. Esta técnica deve ser utilizada após avaliação do tamanho do cisto e da extensão do baço que está sendo ocupada ${ }^{(2)}$.

Cistos epidermóides são vistos, principalmente, em crianças e adultos jovens, propondo-se uma origem congênita para esta doença. Apesar do desconhecimento da histogênese desses cistos, supõem-se que se originariam de inclusão embriogênica de células epiteliais, de estruturas adjacentes, ou de invaginação do mesotélio( ${ }^{(1,3)}$.

Alvarez G da C, Silveira ML da, Costa EM da, Pagliarin FV, Costa I. Epidermoid splenic cyst in children. A case report. Arq Gastroenterol 2000;37(1):69-71.

ABSTRACT - The authors present a case of epidermoid splenic cyst in masculine patient of 13 years, that presented decrease of appetite, fever and alimentary vomits and tangible abdominal mass in the physical exam. Abdominal ultrassonography demonstrated expansible lesion in the topography of the spleen, and computerized tomography revealed intrinsic homogeneous lesion of the spleen, without communication with pancreas. To the laparotomy, cystic mass of great extension was observed, submited total esplenectomy, being diagnosed in the histopatological exam epidermoid splenic cystic. In the follow-up patient developed with disappearance of the symptoms. The epidermoid splenic cyst are rare, they can be seen mainly in children and young adults, what proposes a congenital origin for this disease.

HEADINGS - Epidermal cyst. Spleen. Child.

\section{REFERÊNCIAS BIBLIOGRÁFICAS}

1. Alvarez GC, Costa EM, Faria EN. Cisto esplênico não-parasitário e não-neoplásico. Rev Col Bras Cir 1998;25:64-5.

2. Golinski D, Freud E, Steinberg R, Zer M. Vertical partial splenectomy for epidermoid cyst. J Pediatr Surg 1995;30:1704-5.

3. Hoffman E. Non-parasitic splenic cysts. Am J Surg 1957;93:765-70.
5. Mielle V, Galluzo M, Cortese A, Bellussi A, Valenti M. Diagnostic imaging of splenic cysts in children. Radiol Med 1998;95:62-5.

6. Tsakayannis DE, Mitchell K, Kozakewich HP, Shamberger RC. Splenic preservation in the management of splenic epidermoid cysts in children. J Pediatr Surg 1995;30:1468-70.

7. Zhurilo IP, Litovka VK, Kononuchenko VP, Moskalenko VZ. Nonparasitics cysts of the spleen in children. Khirurgiia $1993 ;(8): 59-62$.
4. Liew SH, Clements WD, Wilson BG. Splenic conservation in the management of large splenic cysts: case report and literature review. J R Coll Surg Edinb 1997;42:135-7.
Recebido para publicação em 28/6/1999. Aprovado para publicação em 19/8/1999. 